\title{
Tree Cover Mapping Tool—Documentation and User Manual
}

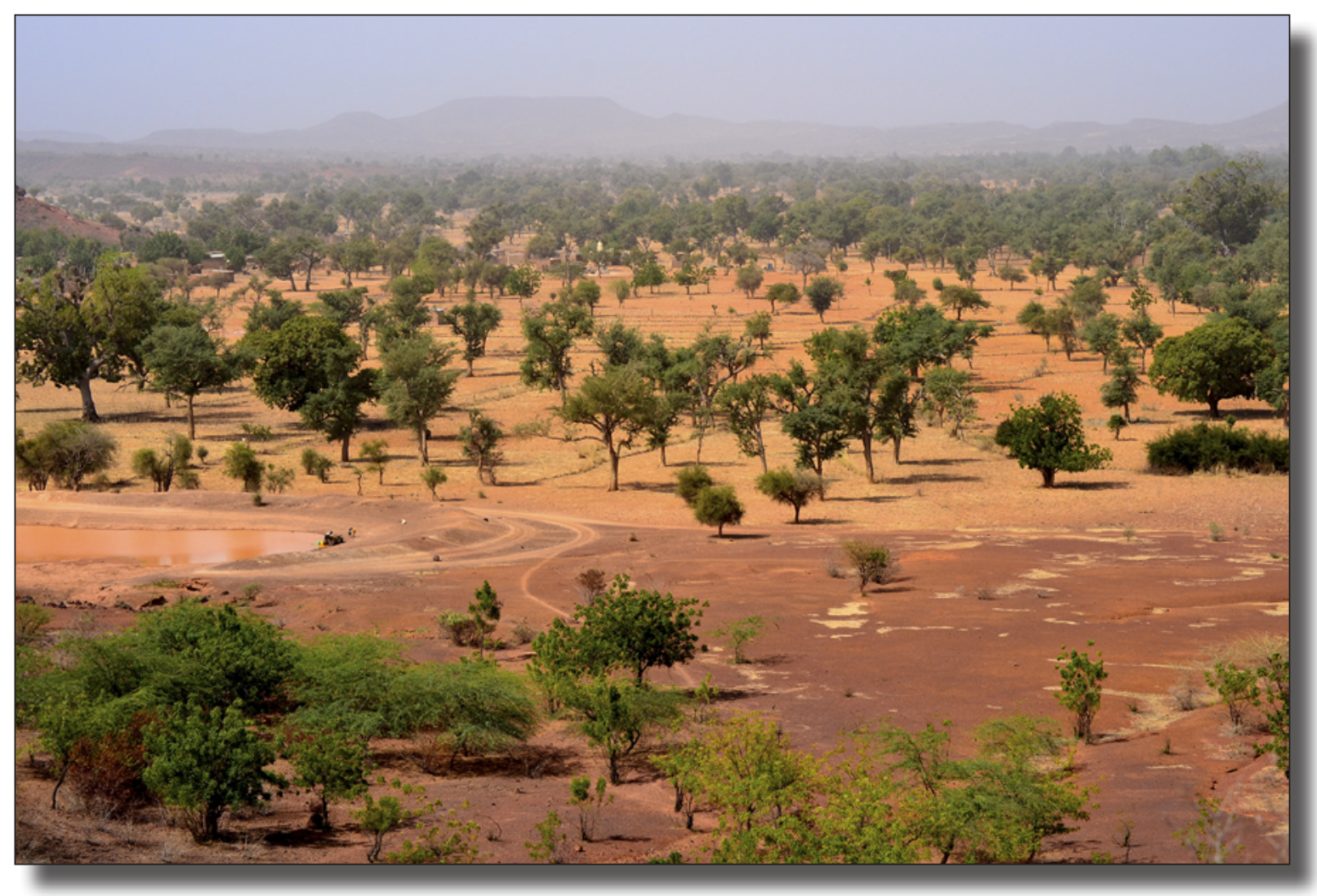

Open-File Report 2016-1067 
Cover. Agroforestry parkland in central Burkina Faso. 


\section{Tree Cover Mapping Tool—Documentation and User Manual}

By Suzanne Cotillon and Melissa Mathis

Open-File Report 2016-1067

U.S. Department of the Interior

U.S. Geological Survey 


\title{
U.S. Department of the Interior SALLY JEWELL, Secretary
}

\section{U.S. Geological Survey Suzette M. Kimball, Director}

\author{
U.S. Geological Survey, Reston, Virginia: 2016
}

For more information on the USGS - the Federal source for science about the Earth, its natural and living resources, natural hazards, and the environment—visit http://www.usgs.gov or call 1-888-ASK-USGS.

For an overview of USGS information products, including maps, imagery, and publications, visit http://store.usgs.gov.

Any use of trade, firm, or product names is for descriptive purposes only and does not imply endorsement by the U.S. Government.

Although this information product, for the most part, is in the public domain, it also may contain copyrighted materials as noted in the text. Permission to reproduce copyrighted items must be secured from the copyright owner.

Suggested citation:

Cotillon, Suzanne, and Mathis, Melissa, 2016, Tree cover mapping tool—documentation and user manual (ver. 1.0, March 2016): U.S. Geological Survey Open-File Report 2016-1067, 11 p., http://dx.doi.org/10.3133/ofr20161067.

ISSN 2331-1258 (online) 


\section{Contents}

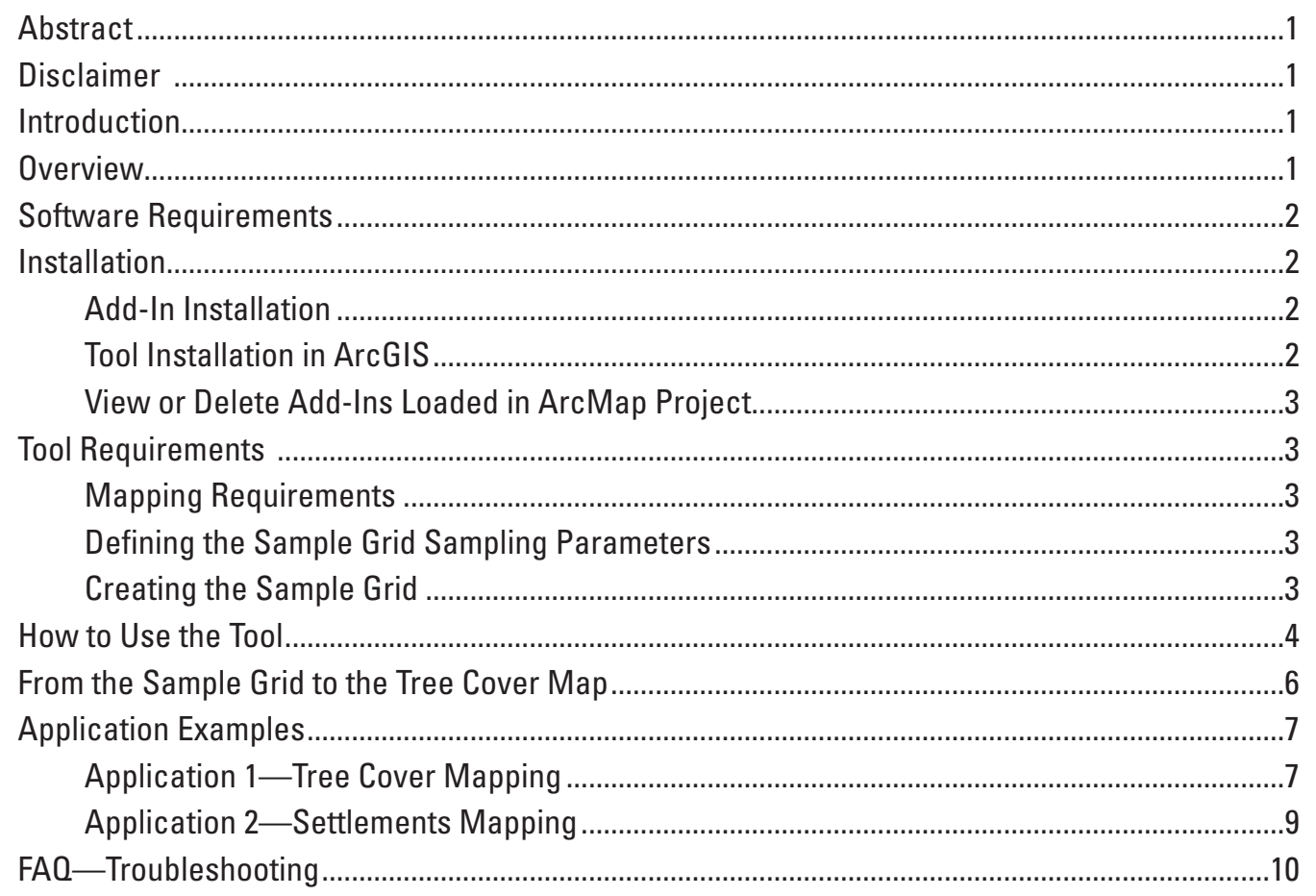




\section{Figures}

1. Flow chart showing overview of the Tree Cover Mapping tool process flow....................2

2. Screen capture of ArcGIS Installation Utility.....................................................................

3. Screen capture of Add Tree Cover Mapping button to toolbar ...........................................3

4. Screen capture of inputs required to create a systematic sample grid using the "Create Fishnet" ArcToolbox.

5. Simplified map showing example of a 4-kilometer systematic sample grid over a study area in south central Niger ................................................................................... 4

6. Screen capture of Tree Cover Mapping tool........................................................................5

7. Screen capture of example of a sample frame and the calibrating dot grid over high resolution imagery ........................................................................................................ 5

8. Screen capture of examples of tree cover density classes. The user must define the categories based on the needs and characteristics of the study area .......................6

9. Screen capture of sampling parameters and corresponding fields in the sample grid attribute table

10. Screen capture of Feature to Raster Inputs...................................................................6

11. Map showing example of a 4-kilometer tree cover density raster map from a systematic sample grid (1 sample every 4-kilometers) over a study area in south-central Niger

12. Maps showing example of on-farm tree cover raster map in the RISE zones of Niger and Burkina Faso.

13. Maps showing example of average on-farm tree cover map by commune in the RISE zones of Niger and Burkina Faso

14. Maps showing example of a heat map of on-farm tree cover in the RISE zones of Niger and Burkina Faso.

15. Simplified map showing settlements coverage in Unity State, South Sudan 


\section{Conversion Factors}

U.S. customary units to International System of Units

\begin{tabular}{lcl}
\hline \multicolumn{1}{c}{ Multiply } & By & \multicolumn{1}{c}{ To obtain } \\
\hline centimeter $(\mathrm{cm})$ & Length & inch (in.) \\
millimeter $(\mathrm{mm})$ & 0.3937 & inch (in.) \\
meter $(\mathrm{m})$ & 0.03937 & foot (ft) \\
kilometer $(\mathrm{km})$ & 3.281 & mile (mi) \\
meter $(\mathrm{m})$ & 0.6214 & yard (yd) \\
\hline & 1.094 & \\
\hline square meter $\left(\mathrm{m}^{2}\right)$ & Area & acre \\
hectare (ha) & 0.0002471 & acre \\
square kilometer $\left(\mathrm{km}^{2}\right)$ & 2.471 & acre \\
square centimeter $\left(\mathrm{cm}^{2}\right)$ & 247.1 & square foot $\left(\mathrm{ft}^{2}\right)$ \\
square meter $\left(\mathrm{m}^{2}\right)$ & 0.001076 & square foot $\left(\mathrm{ft}^{2}\right)$ \\
hectare $($ ha) & 10.76 & square mile $\left(\mathrm{mi}^{2}\right)$ \\
square kilometer $\left(\mathrm{km}^{2}\right)$ & 0.003861 & square mile $\left(\mathrm{mi}^{2}\right)$ \\
\hline
\end{tabular}

\section{Abbreviations}

ID identifier

FID feature identifier

GIS geographic information system

RISE Resilience In the Sahel Enhanced

SRO Sahel Regional Office

TCM Tree Cover Mapping

USAID U.S. Agency for International Development

USGS U.S. Geological Survey

UTM Universal Transverse Mercator 



\title{
Tree Cover Mapping Tool—Documentation and User Manual
}

\author{
By Suzanne Cotillon' and Melissa Mathis ${ }^{1}$
}

\section{Abstract}

The Tree Cover Mapping (TCM) tool was developed by scientists at the U.S. Geological Survey Earth Resources Observation and Science Center to allow a user to quickly map tree cover density over large areas using visual interpretation of high resolution imagery within a geographic information system interface. The TCM tool uses a systematic sample grid to produce maps of tree cover. The TCM tool allows the user to define sampling parameters to estimate tree cover within each sample unit. This mapping method generated the first on-farm tree cover maps of vast regions of Niger and Burkina Faso. The approach contributes to implementing integrated landscape management to scale up re-greening and restore degraded land in the drylands of Africa. The TCM tool is easy to operate, practical, and can be adapted to many other applications such as crop mapping, settlements mapping, or other features. This user manual provides step-by-step instructions for installing and using the tool, and creating tree cover maps. Familiarity with ArcMap tools and concepts is helpful for using the tool.

\section{Disclaimer}

This software has been approved for release by the U.S. Geological Survey (USGS). Although the software has been subjected to rigorous review, the USGS reserves the right to update the software as needed pursuant to further analysis and review. No warranty, expressed or implied, is made by the USGS or the U.S. Government as to the functionality of the software and related material nor shall the fact of release constitute any such warranty. Furthermore, the software is released on condition that neither the USGS nor the U.S. Government shall be held liable for any damages resulting from its authorized or unauthorized use.

The user of this software must acquire high resolution imagery before using the tool.

${ }^{1}$ SGT Inc., Contractor to the U.S. Geological Survey, Contract G15PC00012

\section{Introduction}

Accurately mapping and monitoring tree cover over vast areas represent a real challenge. There are a variety of satellite-derived data that provide information about tree cover over broad spatial extents, but most data are based on satellite sensors with resolutions too coarse to observe isolated trees or regeneration of trees or both. In dryland areas like the Sahel, Africa, where trees are rare and sparse, satellitederived methods, such as automatic or semi-automatic spectral classifications, are not effective to accurately map tree cover. The Tree Cover Mapping (TCM) tool is a ArcGIS Add-In that was created to facilitate tree cover mapping at a large scale using visual interpretation of high resolution imagery. The tool provides the infrastructure for a user to estimate tree cover (in percent) within a defined sample frame. The TCM tool aims to (1) facilitate panning and zooming to each sample, (2) help estimate tree cover within a defined sample frame by creating a calibrating dot grid over each sample, (3) enable ArcMap extent to synchronize with Google Earth, and (4) generate a map based on sample points. This user manual provides step-by-step instructions for installing and using the TCM tool, including creating raster maps. The manual also presents examples of output products and illustrations of additional applications.

\section{Overview}

The Tree Cover Mapping tool (hereinafter tool) is developed for the ArcGIS 10.x software by Environmental Systems Research Institute (Esri). The tool was created in VB.NET using Microsoft Visual Studio as a custom Add-In for ArcMap. It was developed and tested on systems running Microsoft Windows 7. The tool should function with other operating systems supported by ArcGIS 10.x. The TCM tool is simple to install and use, but requires creating a point grid feature layer before mapping. Before using the tool, the user must create a point sample grid, which will be used through the mapping process using the TCM tool and high resolution images. After all the samples are attributed, the user can convert the sample grid to a raster map. 


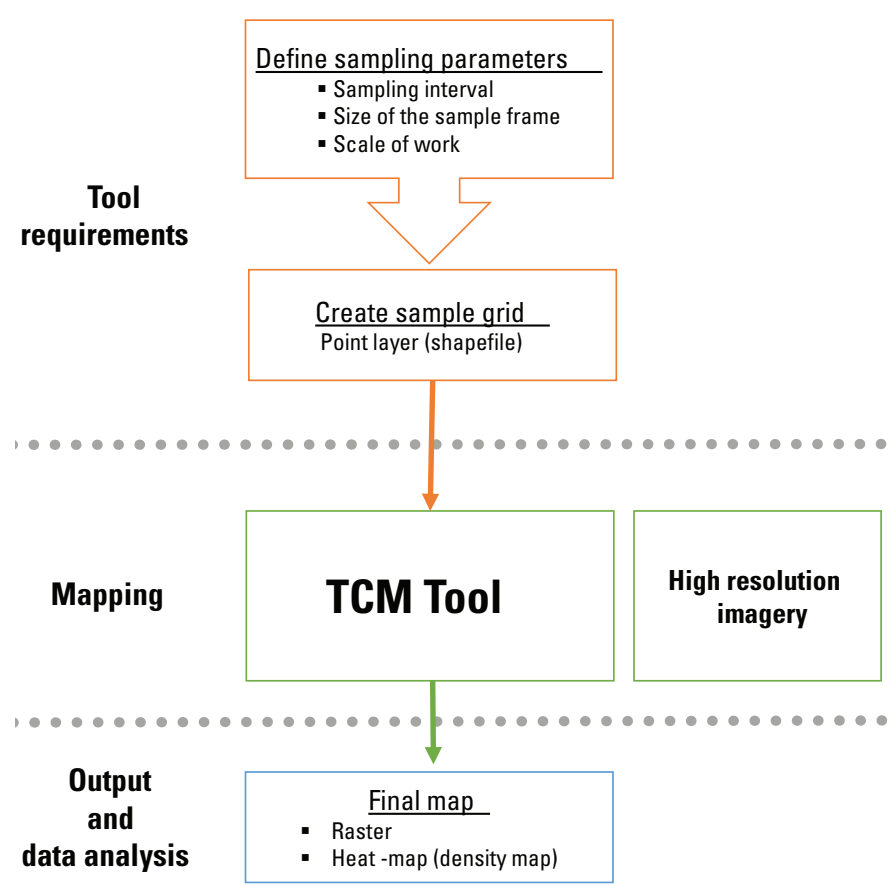

Figure 1. Overview of the Tree Cover Mapping (TCM) tool process flow.

\section{Software Requirements}

ArcGIS 10.1 or higher and Google Earth are required to use the TCM tool. Individual TCM Add-Ins are available for each version. The TCM tool will automatically open and synchronize ArcGIS's window extent with Google Earth's imagery. The tool is most effective when using high resolution imagery sources from Arc2Earth, Esri's World View image service, ArcBruTile, but other high resolution imagery sources work as well. The TCM tool was tested with Arc2Earth.

Arc2Earth is an extension used to display Google and Bing base maps in ArcGIS, created by the company Arc2Earth, LLC. The extension is simple to install and adds a Google and Bing toolbar to ArcGIS. The extension requires a monthly subscription and can be purchased online at http:// www.arc2earth.com. Arc2Earth creates tile caches on the user's local hard drive, which allows the images to draw and refresh quickly.

The TCM tool seems to perform best when using the locally stored tile caches. The TCM tool was tested with other high resolution imagery sources such as Esri's image services, but they did not perform as well because of the absence of tile caching.

\section{Installation}

The TCM tool is an ArcGIS Add-In that provides custom functionality to ArcMap. Before installing the Add-In, close all open ArcMap applications.

\section{Add-In Installation}

1. Double-click on the "TreeCoverMapping.esriAddIn" file. The TCM Add-Ins are available from the authors upon request.

2. Click "Install Add-In" on the Esri ArcGIS Add-In Installation Utility screen.

3. Click Ok at the Installation succeeded prompt.

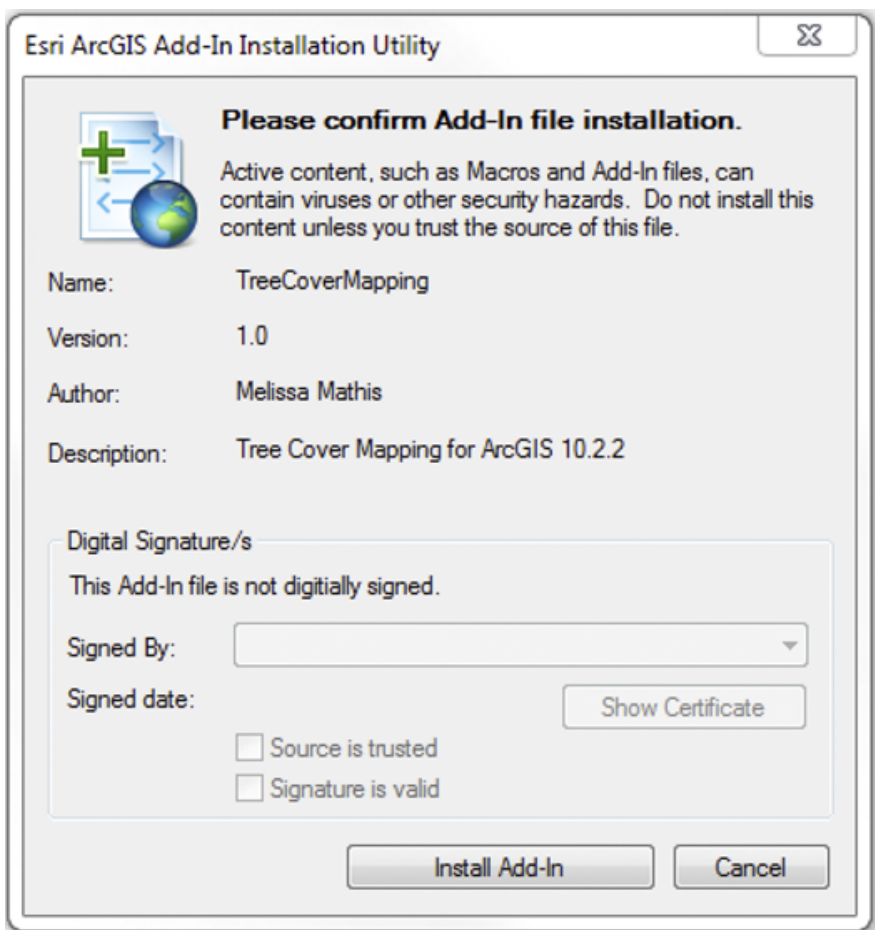

Figure 2. ArcGIS Installation Utility.

Installed Add-Ins are stored in the folder:

C: \Users $\backslash$ User Name $\backslash$ Documents $\backslash$ ArcGIS $\backslash A d d I n s \backslash$

Desktop10.x.ArcMap automatically locates the Add-In in this folder upon opening.

\section{Tool Installation in ArcGIS}

1. Open ArcMap.

2. Choose Customize $>$ Customize Mode.

3. Select the Commands tab, under the Categories section, choose "Resiliency Tools".

4. Under the Commands window a "Tree Cover Mapping" item will appear. Left click and hold the "Tree Cover Mapping" item, and drag it to the ArcMap toolbar (fig. 3).

5. Right click on the tree icon and a menu will appear. To view text and your tree icon, choose the Image and Text item. 


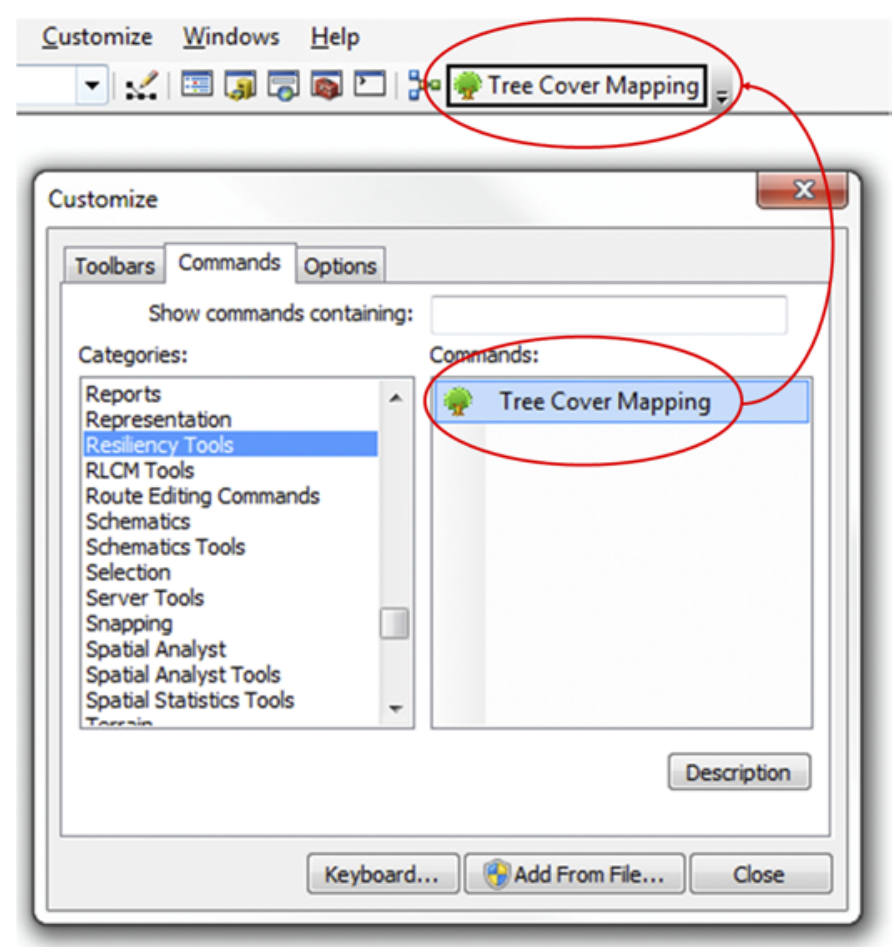

Figure 3. Add Tree Cover Mapping button to toolbar.

\section{View or Delete Add-Ins Loaded in ArcMap Project}

1. Choose Customize $>$ Add-In Manager.

2. In the Add-In Manager window you can view and delete all the Add-Ins installed under your project.

\section{Tool Requirements}

Ensure Google Earth is open and running. Google Earth will automatically synchronize its location and extent with the ArcMap's extent.

\section{Mapping Requirements}

The approach to tree cover mapping is sample based. The user must create a systematic sample grid over the study area to create a map of tree cover density. In systematic and grid sampling, samples are taken at regularly spaced intervals. The sample grid, which is a point shapefile, defines the precision of the analysis and the resolution of the output map.

\section{Defining the Sample Grid Sampling Parameters}

As mentioned in the "Mapping Requirements" section, the user must define the sampling parameters of the sample grid. Because tree cover mapping must be done using high resolution imagery to be able to see the trees, the mapping scale usually ranges from 1:6,000 to $1: 2,000$. The user must find the balance between the number of samples desired for the mapping analysis, the level of precision of the output map (final resolution), the desired confidence level, and the level of effort that can be dedicated to the mapping exercise.

1. The sampling interval is the distance between each sample (point) that will define the resolution of the output map. The sampling interval also influences the number of samples over the study area.

2. The size of each sample frame in which the user estimates tree cover. The size of the frame depends on the mapping scale. For instance, at a mapping scale of $1: 6,000$ to $1: 2,000$, the frame has to be between 0.1 and 2 square kilometers (that is, between 310 and 1,300 meters in length).

3. The scale of work (mapping scale).

\section{Creating the Sample Grid}

1. In the ArcToolbox, choose Data Management Tools $>$ Feature Class $>$ Create Fishnet (figs. 4 and 5).

2. Enter a name for your sample grid (Output Feature Class).

3. Choose a template extent, to define the study area over which the sample grid will be created and used for mapping. The extent can be entered by specifying coordinates in the "Fishnet Origin Coordinate" boxes or using a template dataset. 
4. Enter the cell size in meters, which is your sampling interval. No need to specify the number of rows or columns.

5. Check "create label points". The resulting point layer is the systematic sample grid layer to use for the mapping.

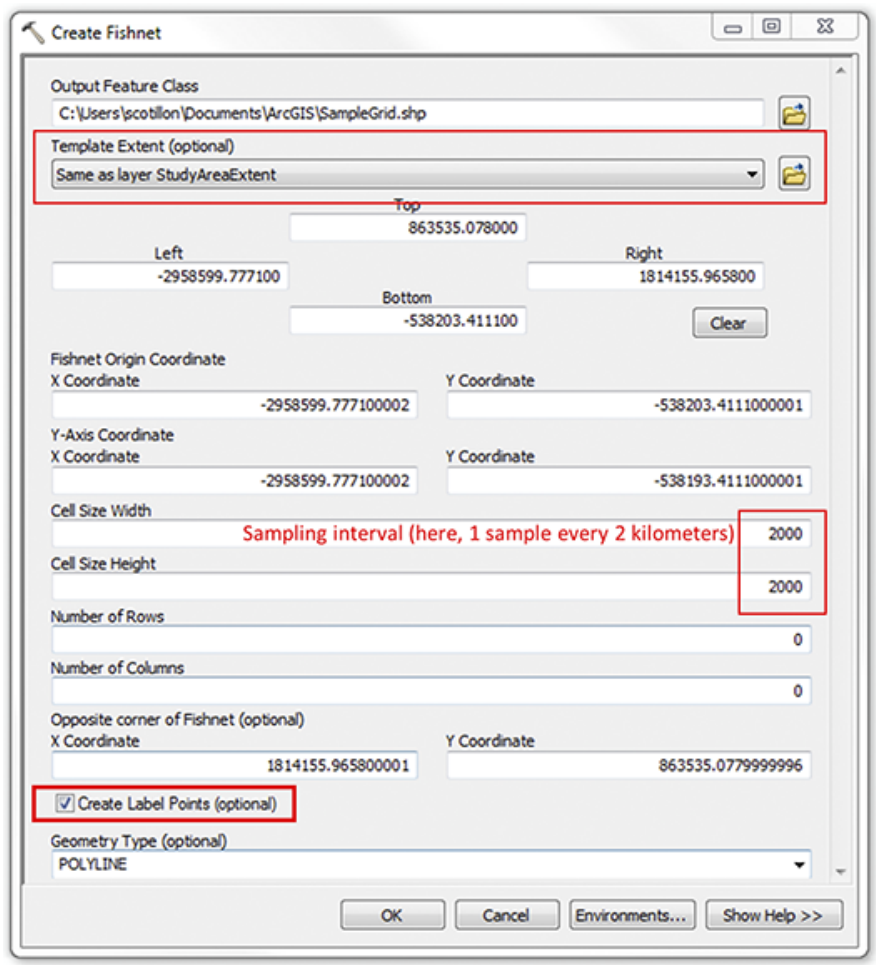

Figure 4. Inputs required to create a systematic sample grid using the "Create Fishnet" ArcToolbox.
6. Select the Environments tab $>$ Output Coordinates, make sure the "Output Coordinate System" is in meters. The sample grid layer must have a Projected Coordinate System (in meters), for example Universal Transverse Mercator (UTM). Unprojected or Geographic Coordinate Systems will not work.

7. Click "OK."

Two layers will be created over the study area: a point layer, which is the sample grid, and a polygon or polyline layer that can be deleted.

8. The last step is to create a "Tree Cover" field in the attribute table of the sample grid layer where the tree cover value will be recorded, for each sample. This new field must be an integer. Open the sample grid layer's attribute table, click on the Table $>$ Add Field. Specify a name, select Short Integer for the Field Type and click "OK."

\section{How to Use the Tool}

For the tool to work properly, the coordinate system of the data frame and the sample grid layer must have the same projected coordinate system.

1. Click on the "Tree Cover Mapping" tool button in the ArcMap toolbar.

2. In the "Tree Cover Mapping" tool window, select the sample grid layer and the sampling parameters (fig. 6).

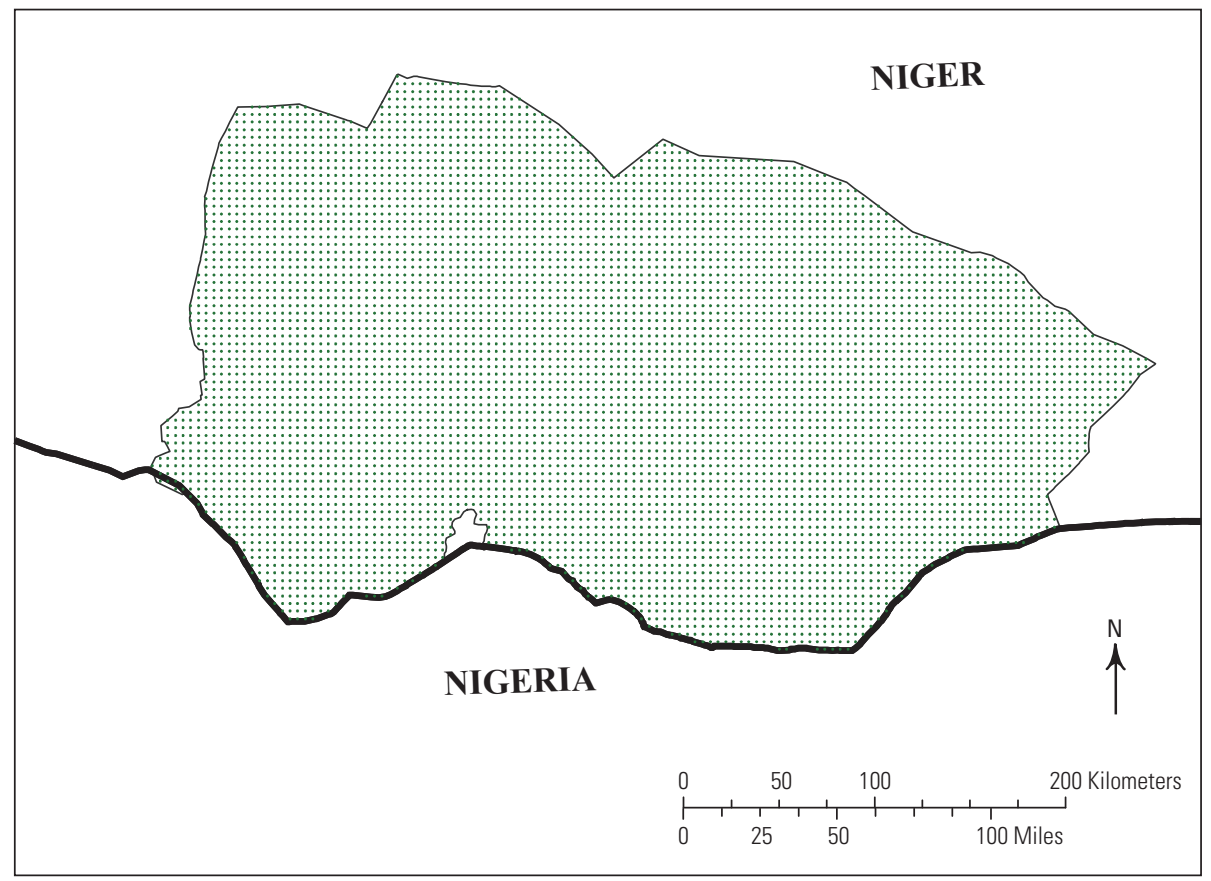

Figure 5. Example of a 4-kilometer systematic sample grid over a study area in south central Niger. 
3. $\triangle$ Before attributing the first sample point in ArcMap, the tool needs to be initiated. The user must manually SELECT and zoom in to the first sample point to the mapping scale, and enter the first tree cover value in the "Tree Cover Value" box. Then, click "Next" or press the "Enter" key. If the first tree cover value needs to be reviewed, click on "Previous".

A FormInputData.txt text file is automatically created in the same directory as the sample grid layer. This text file records the input data and the last sample that has been attributed. DO NOT DELETE the FormInputData. txt. When mapping a new project for the first time, if the
FormInputData.txt file exists, delete it. The .txt file will be created after the first sample point is attributed.

4. In each sample, the user estimates the tree cover value based on the number of dots (red dots of the calibrating grid) that touch the canopy of a tree. This value is an estimate of the percent of tree canopy cover within each sample frame (figs. 7 and 8).

5. After clicking "Next", the tree cover value entered by the user is saved in the attribute table of the sample grid layer in the "Tree cover" field. A new field, "Attributed", is automatically created in the sample grid attribute table. The "Attributed" field records which samples have been attributed and which have not. The number "1" represents attributed samples (fig. 9).

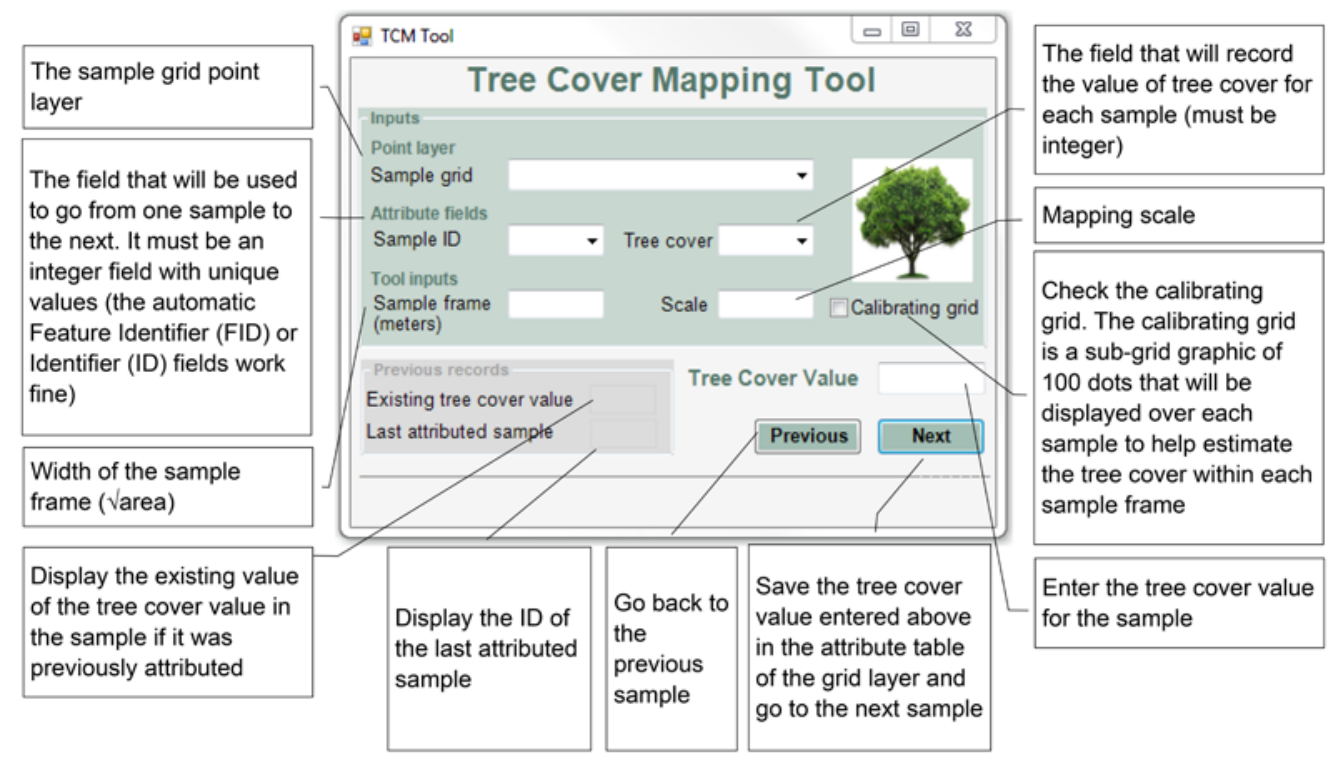

Figure 6. Tree Cover Mapping tool.

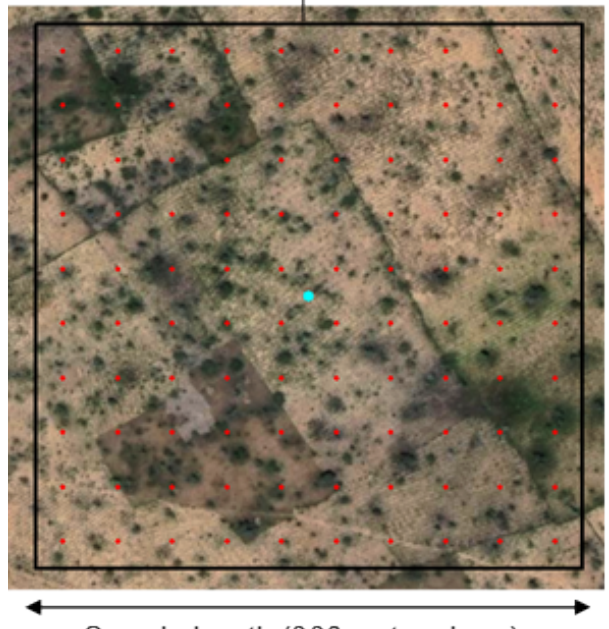

Sample length (330 meters here)

Figure 7. Example of a sample frame and the calibrating dot grid (graphic) over high resolution imagery. 


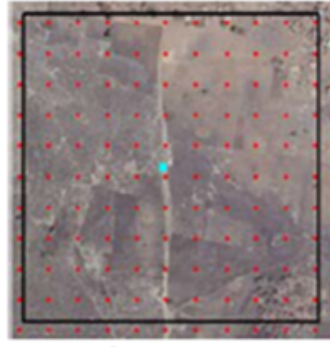

0 percent No tree cover

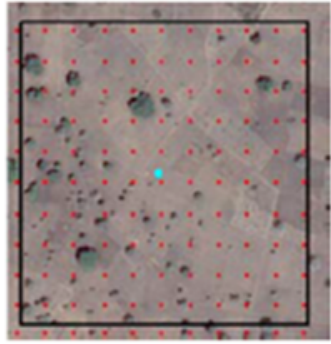

1-5 percent Very low tree cover

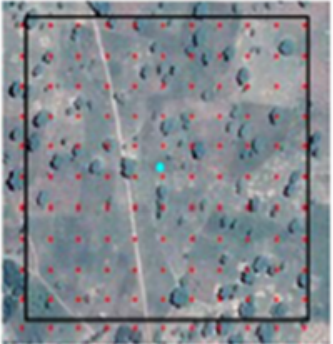

6-10 percent Low tree cover

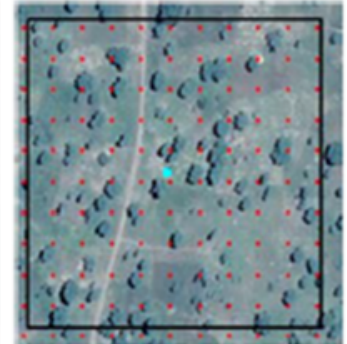

11-15 percent Medium tree cover

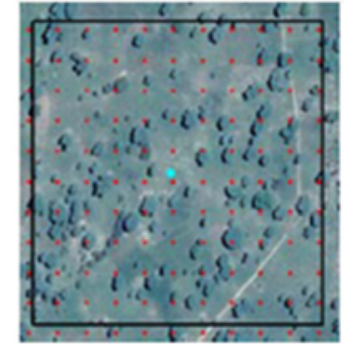

Greater than 15 percent High tree cover

Figure 8. Examples of tree cover density classes. The user must define the categories based on the needs and characteristics of the study area.

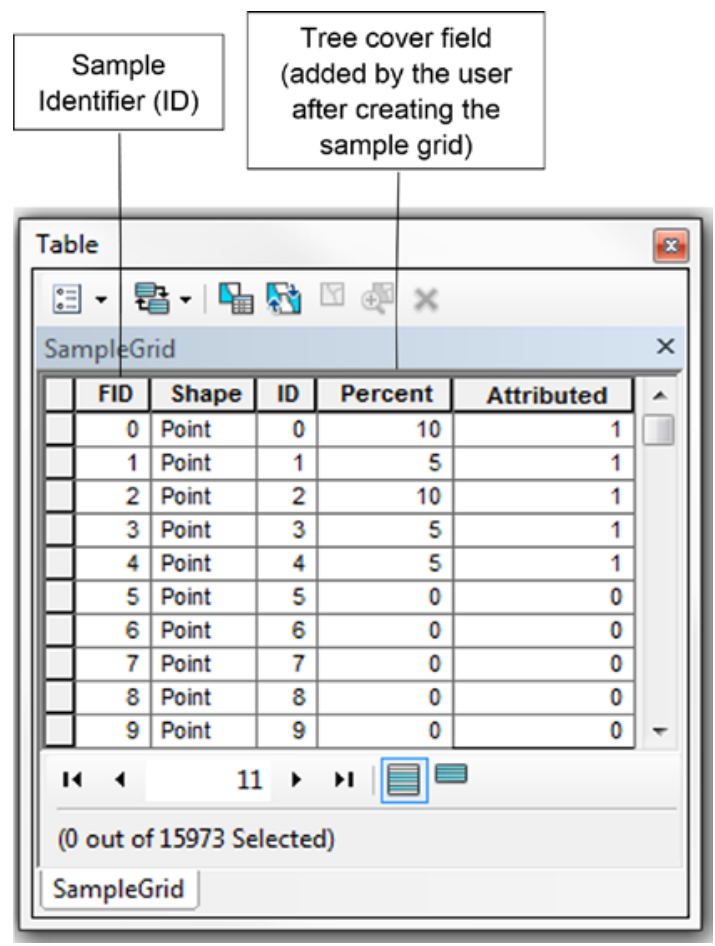

Figure 9. Sampling parameters and corresponding fields in the sample grid attribute table.

\section{From the Sample Grid to the Tree Cover Map}

Once all the points of the sample grid are attributed, the user can convert the systematic sample grid to a raster.

1. In the ArcToolbox, choose Conversion Tools $>$ To Raster $>$ Feature to Raster (figs. 10 and 11).

2. Choose the sample grid layer from the Input features drop down box.

3. Select the Field from which the raster will be created (the "Tree Cover" integer field).

4. Select the "Output cell size", which is the sampling interval (that is, the resolution of the output map).

Because the sample grid is a systematic point layer, additional geographic information system (GIS) analysis can be done, such as Zonal Statistics and heatmaps (using Kernel Density or Point Density functions) (see application examples).

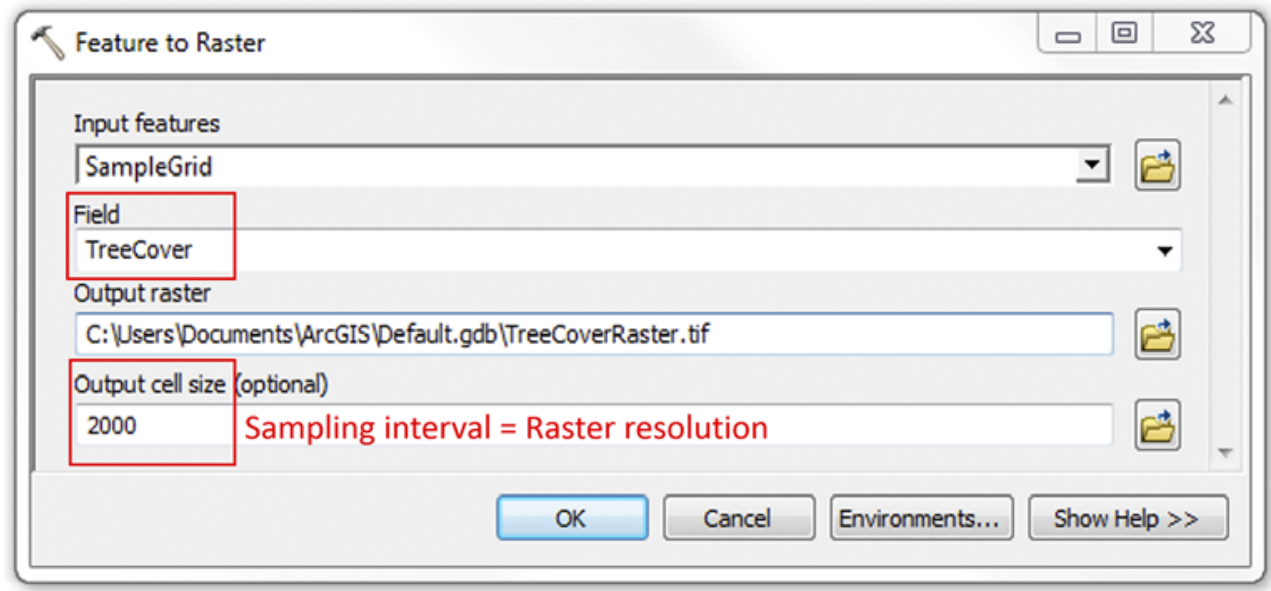

Figure 10. Feature to Raster Inputs. 


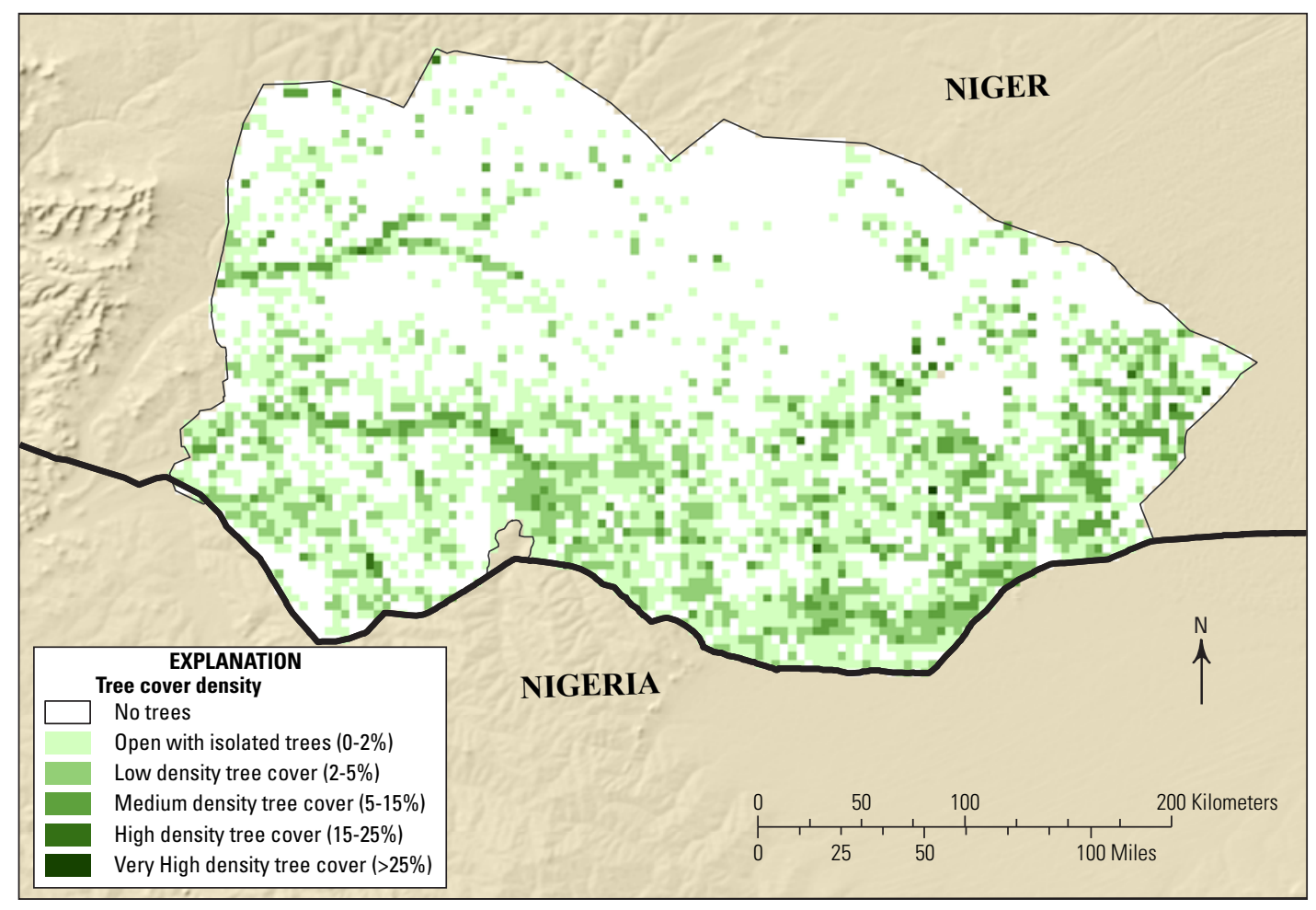

Figure 11. Example of a 4-kilometer tree cover density raster map from a systematic sample grid (1 sample every 4-kilometers) over a study area in south-central Niger.

\section{Application Examples}

\section{Application 1-Tree Cover Mapping}

Title: On-farm tree cover mapping in Burkina Faso and Niger Purpose: Baseline mapping of on-farm tree cover in some regions of Burkina Faso and Niger to support the U.S. Agency for International Development/ Sahel Regional Office (USAID/SRO)—Resilience In the Sahel Enhanced (RISE) program.

Study Area: 175 communes covering 235,200 square kilometers
Imagery source: Bing maps and Google Earth from Arc2Earth (2012 to 2014)

Sampling Parameters:

- Sampling interval: 2,000 meters

- Size of the sample frame: 330 meters

- Mapping scale: 1:3,000

- Total number of samples: 29,757 points

Mapping time: About 1 month

Output maps: (figs. 12, 13, and 14) 

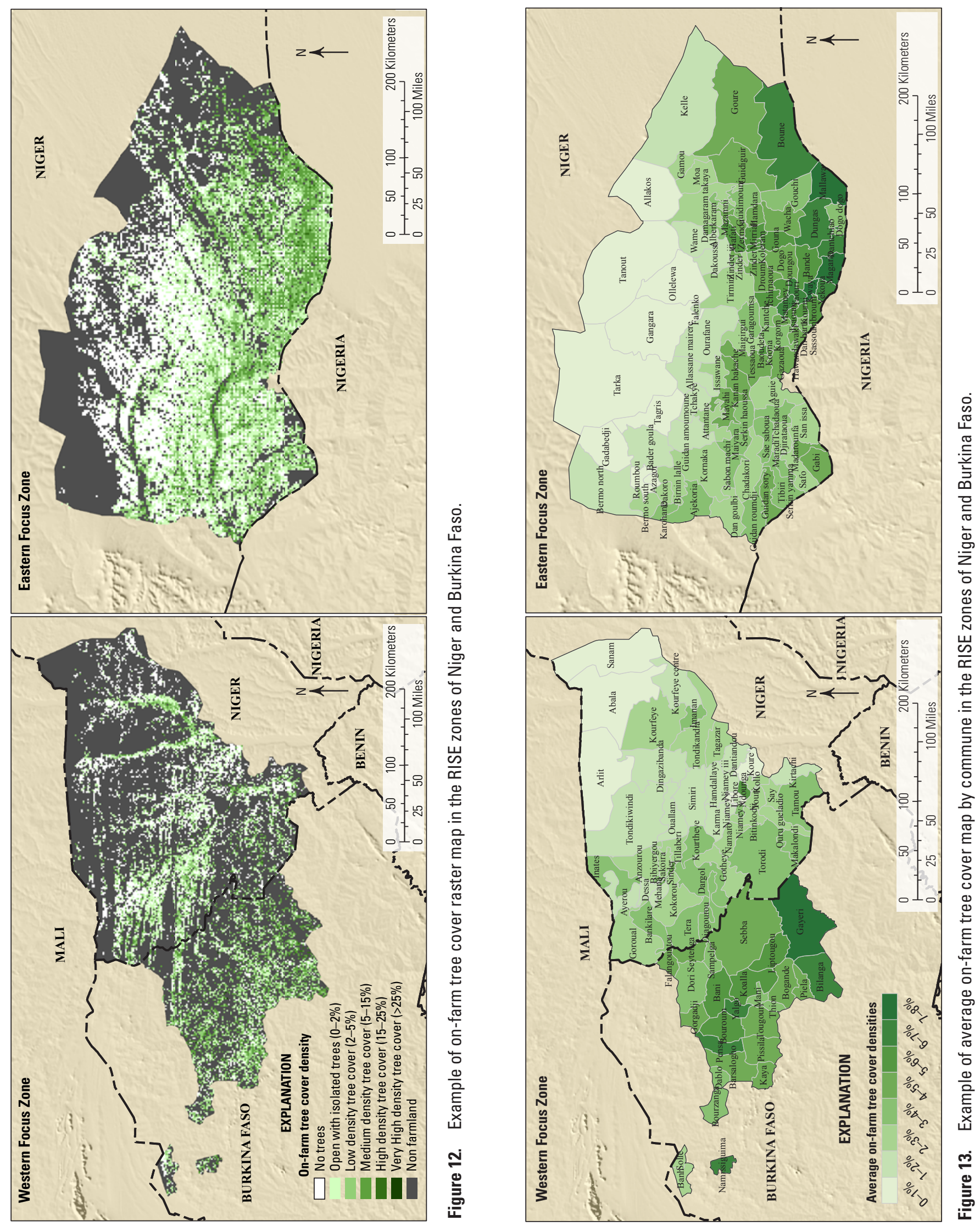


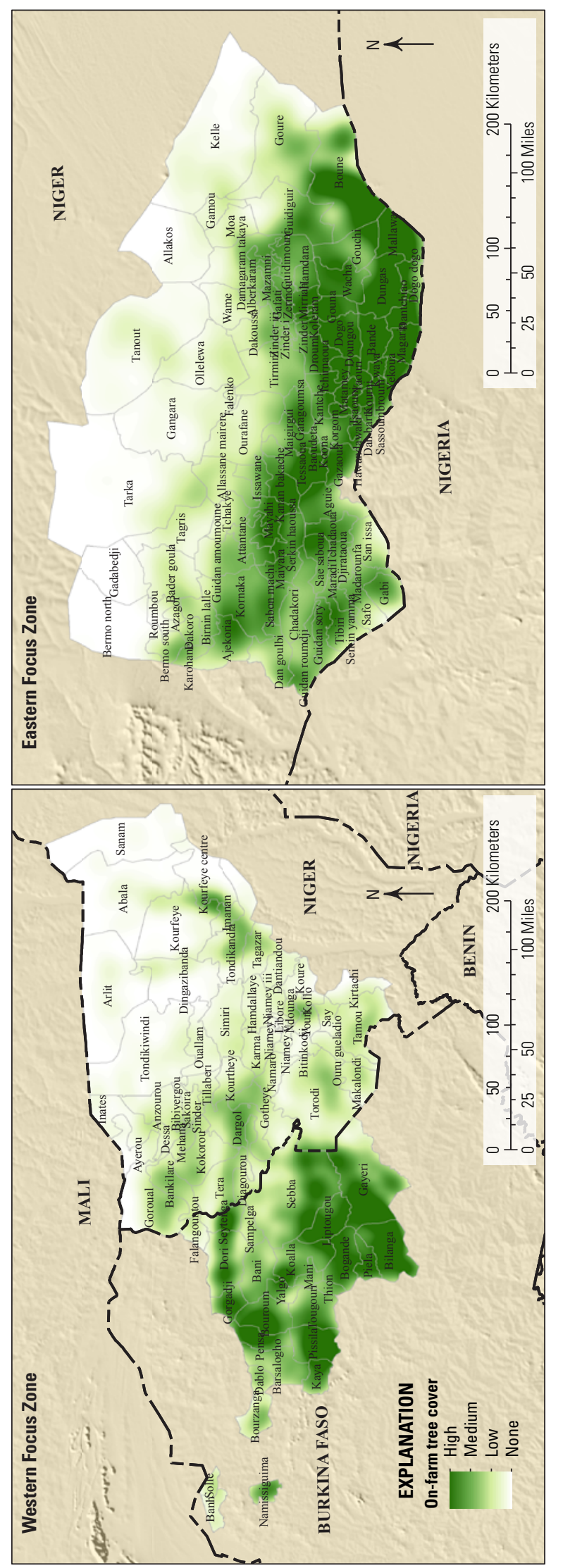

\section{Application 2-Settlements Mapping}

Similarly to trees, settlements in rural areas can be challenging to map using automated/semi-automated classifications of spectral images. The TCM tool facilitates using visual interpretation of high resolution imagery to estimate settlements density over large areas.

Title: Settlements mapping in Unity State in South Sudan Purpose: Baseline mapping of settlements density in a conflict area in South Sudan, in support of the U.S. Geological Survey/ Famine Early Warning System program.

Study Area: 4 communes in Unity State, South Sudan: 12,500 square kilometers

Imagery source: Bing maps and Google Earth from Arc2Earth (2011 to 2014)

Sampling Parameters:

- Sampling interval: 2,000 meters

- Size of the sample frame: 2,000 meters

- Mapping scale: 1:9,400

- Total number of samples: 3,242 points

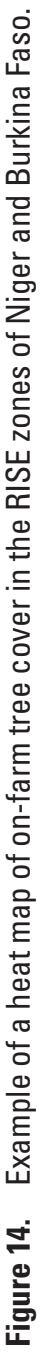

Mapping time: 6 hours

Output raster map: (fig. 15)

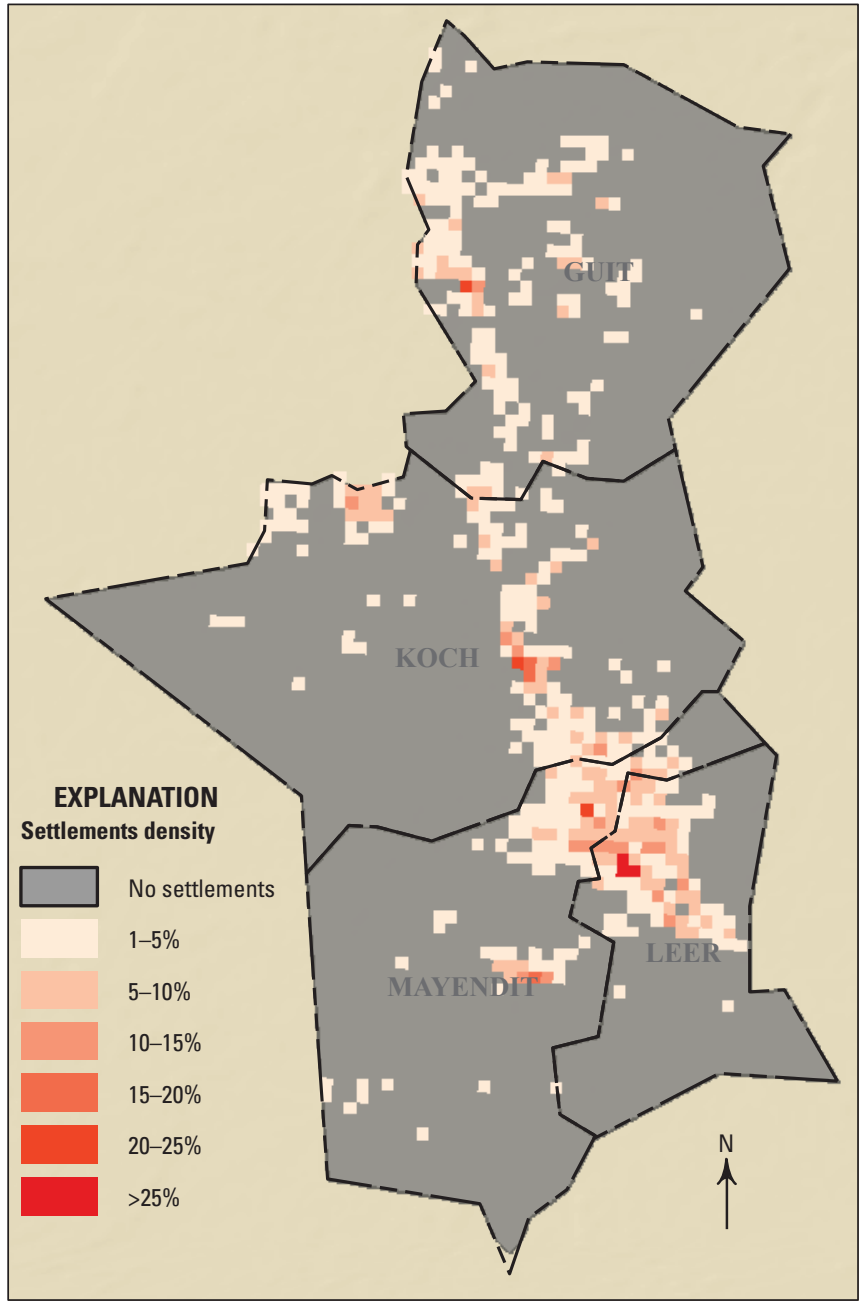

Figure 15. Settlements coverage in Unity State, South Sudan. 


\section{FA0-Troubleshooting}

\section{Why does my ArcMap project crash?}

Sometimes creating the calibrating grid causes ArcMap to crash because of a projection issue. Make sure the data frame and the sample grid layer are projected (in meters), for example in a coordinate system Universal Transverse Mercator (UTM).

Find more about projecting data in ArcGIS at http://support. esri.com/de/knowledgebase/techarticles/detail/20118. Make sure Google Earth is open and running before using the tool.

I received a new version of the Tree Cover Mapping (TCM) tool, how do I install it?

Delete the old Add-In before installing the update. In ArcMap, choose Customize > Add-In Manager > Add-Ins tab. Select the Add-In to delete and click on the "Delete this Add-In" button. Then, install the new Add-In as described in the instructions (see Installation section).

\section{I get an Inputs Unhandled Exception Error, how do I fix it?}

Click on the "Continue" button and make sure Google Earth is running before using the TCM tool.

\section{Why doesn't the Calibrating Grid draw?}

The calibrating grid does not draw as soon as the checkbox in the TCM tool is clicked. It only draws when the "Next" or "Previous" buttons are clicked.

Can the calibrating dot grid and frame generated around each sample point be disabled and re-enabled, that is, turned off and on, and if so, how?

The calibrating grid (red dots) can be turned off by unchecking the "Calibrating grid" checkbox in the TCM tool.

The black frame is always visible and cannot be turned off, but because it is a graphic it can be selected and deleted manually.

\section{Can I return to the last sample point I attributed?}

Yes, use the "Previous" button located near the "Next" button. The "Previous" button will take you to the previous sample and the value that you previously attributed. The sample value is visible under the "Existing Tree Cover Value" text.

\section{Is it possible to reorder the samples?}

Yes, first create a new integer Identifier (ID) field in your sample grid attribute table. Toggle the sample grid layer into editing mode. Then select your samples over one image and manually change their ID (from 1 to 20 for example). You can also use the Field Calculator from the sample grid layer attribute table and automatically generate an ordered ID as described here: http://support.esri.com/en/knowledgebase/ techarticles/detail/38517.

The ID field must be ordered in a numeric sequence for the tool to work efficiently.

Change your "Sample ID" field on the TCM tool input form.

Is it possible to attribute a temporary value in the Tree Value field? Or to jump to one sample ID without inserting a value, or to signal that the sample ID must be reanalyzed?

Yes, it is possible as long as the entered value is a number. For example, use 99 or 999 . Then you can easily find these samples in the attribute table and query them.

See select records by attribute: $h t t p: / / h e l p$. arcgis.com/EN/ARCGISDESKTOP/10.0/HELP/index. html\#//001700000071000000.

\section{Can I change the map scale on the TCM tool input form?}

Yes, the scale value can be changed on the TCM tool input form, see How to Use the Tool section.

Do all of my layers in the ArcMap document need to be projected?

No, only the data frame projection and the sample grid layer projection are required to be in meters for the TCM tool to work properly. The UTM projection is an example of a coordinate system stored in meters.

\section{Why does it take so long to move from one point to} the next?

The imagery source may be causing the TCM tool to perform slowly. A tiled imagery source or image base map is recommended. The tool was tested with Google and Bing services from Arc2Earth.

\section{Where can I learn more about Arc2Earth?}

Arc2Earth is an extension used to display Google and Bing base maps in ArcGIS, created by the company Arc2Earth, LLC. The extension is simple to install and adds a Google and Bing toolbar to ArcGIS. The extension requires a monthly subscription and can be purchased online at http:// www.arc2earth.com. Arc2Earth creates tile caches on the user's local hard drive, which allows the images to draw and refresh quickly.

Can I use my own high resolution imagery with the TCM tool?

Yes, the TCM tool has been tested using only Arc2Earth, but is intended to accommodate other imagery such as Esri's World View image service, ArcBruTile, as well as any high resolution imagery sources. 
In ArcGIS 10.0 or later versions, high resolution imagery display performance can be enhanced by adding your imagery into a basemap layer. See the link below for more information: http:/help.arcgis.com/En/Arcgisdesktop/10.0/Help/index. html\#//00s500000017000000.

The Tree Cover Mapping button disappeared from ArcMap. How do I get it back?

To view or delete an Add-In from your ArcMap project, choose Customize $>$ Add-In Manager $>$ Add-Ins tab. Select the Add-In to delete and click on the "Delete this Add-In" button. Then, re-install the Add-In as described in the instructions (see Installation section). 




\section{$\frac{\mathbb{3}}{3}$}

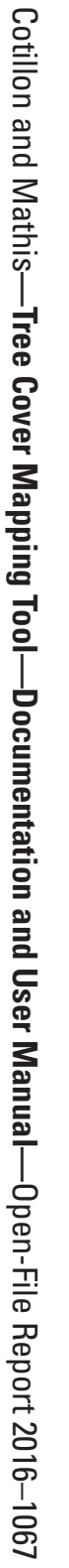

